\title{
Do método do caso ao case: a trajetória de uma ferramenta pedagógica
}

Maria Arlinda de Assis Menezes

Instituto Federal de Educação, Ciência e Tecnologia Baiano

\section{Resumo}

0 presente trabalho procura distinguir os conceitos acerca do método de estudo de casos e o método do caso dentro das Ciências Sociais e suas aplicabilidades, assim como diferenciar o modo empírico/indutivo e o teórico/dedutivo de pensar, sendo apresentado no trabalho como característicos de americanos e alemães respectivamente, fatores que diferenciam o ensino nos dois países. Para tanto, realiza uma descrição sobre o momento do surgimento do método do caso na escola de Direito em Harvard, destacando a conjuntura social, econômica e cultural que possibilitaram a criação desse instrumento pedagógico e, concomitantemente, apresenta o estudo de caso que, como proposto por Yin, cuja obra referenciou o trabalho em questão, se configura em um dos mais utilizados métodos nos estudos científicos, rompendo com o credo de que é um método fácil de ser aplicado, antes, exige do pesquisador dedicação e rigor científico, além de uma elaboração do problema de maneira a não torná-lo óbvio, um simples relato de experiência. Já o método de casos, criado por Christopher Columbus Langdell, não busca a pesquisa empírica como resposta a um determinado problema, antes, é uma ferramenta pedagógica utilizada na formação de advogados, juristas e administradores de empresas em que a teoria é um subsídio à análise de jurisprudências e experiências em administração, não apenas o objetivo puro e simples da academia.

\section{Palavras-chave}

Estudo de caso - Método do caso - Pesquisa científica - Formação acadêmica.

\section{Correspondência:}




\title{
Case method and case study: an epistemological approach
}

\author{
Maria Arlinda de Assis Menezes \\ Instituto Federal de Educação, Ciência e Tecnologia Baiano
}

\begin{abstract}
The present work seeks to draw a distinction between the concepts of Case Method and Case Study within the Social Sciences and their applicability, as well as to differentiate the empirical/inductive and theoretical/deductive modes of thinking, which are presented here as respectively characteristic of Americans and Germans, and as factors that distinguish the education in those two countries. To such end, the text describes the moment when the Case Method appeared in the Harvard Law School, emphasizing the social, economic, and cultural contexts that allowed the creation of this pedagogical instrument. At the same time, it shows the Case Study which, proposed by Yin, and whose work was referenced in that study, turned out to be one of the most often used methods in scientific works, challenging the belief that it is an easy-to-use method; actually, it requires from the researcher dedication and scientific rigor, apart from a formulation of the problem that avoids to make it obvious, a plain report of an experience. On the other hand, the Case Method created by Christopher Columbus Langdell does not go after empirical research as an answer to a given problem, but is a pedagogical tool employed in the training of lawyers, jurists and business administrators, in which theory is but an input for the analysis of jurisprudence and management experiences, and not just the pure and simple objective of academia.
\end{abstract}

\section{Keywords}

Case Study - Case Method - Scientific Research - Academic formation.

\footnotetext{
Contact:

Maria Arlinda de Assis Menezes

Av. José Luiz dos Santos, 326

Resid. Porto Gonçalves, BI. B - apto. 01

48030-450 - Alagoinhas - BA

e-mail: arlinda.menezes@hotmail.com
} 
A proximidade dos termos método do caso e estudo de caso pode, casualmente, levar a uma confusão conceitual por parte de estudantes que estão iniciando seu processo de formação acadêmica. Partindo dessa premissa, procura-se no artigo que ora se apresenta realizar uma abordagem elucidativa sobre o método do estudo de caso muito utilizado em pesquisa social, seguindo-se de uma contextualização histórica sobre a origem do método do caso, um breve comentário sobre a aplicabilidade deste no Brasil e, por último, uma conclusão. Para tal trabalho, utilizou-se o referencial teórico baseado em Conant (1968), Yin (2001), Martins (2006) e Boaventura (2007).

Nesse sentido, busca-se tornar claro que o método do caso não se trata de uma metodologia de pesquisa, como vem a ser o estudo de caso, mas uma ferramenta pedagógica utilizada na formação de advogados, juristas, administradores de empresas, além de esclarecer que, ao contrário do que se pode pensar erroneamente, a escoIha em pesquisas acerca do uso do estudo de caso não ocorre por ser o mais simples, mais fácil, sendo que a exigência de um planejamento e rigor científico são condições imprescindíveis. Seu uso é mais evidenciado em "pesquisas científicas orientadas por avaliações qualitativas; pesquisas qualitativas, como são geralmente denominadas" (Martins, 2006, s/p). Isso pode ser explicado devido à grande variedade de fontes de informações que a escolha pelo estudo de caso pode possibilitar ao pesquisador.

Ainda segundo Martins (2006), a necessidade do rigor científico e do cuidado com a apresentação dos resultados da pesquisa que utiliza o estudo de caso evita que eles se tornem

[...] relatórios enfadonhos, com excesso de detalhes totalmente dispensáveis, cujos resultados em nada surpreendem, pelo contrário, são plenamente conhecidos antes de serem apresentados pelos estudos. (p. 8)

Dando sequência, será apresentado o método do caso e a história de seu surgimento na Escola de Direito da Universidade de Harvard, re- volucionando a forma de conduzir o ensino de advogados, juristas e administradores de empresa.

Langdell foi o inventor de um precioso instrumento pedagógico, o método do caso, com grande impacto no meio universitário e profissional do pós-guerra civil. Introduziu no ensino do Direito, utilizando uma seleção de casos sobre a lei dos contratos. 0 método do caso representava, assim, no ensino jurídico, considerável efeito prático, empírico e indutivo de pensar e praticar o ensino jurídico. (Boaventura, 2007, p. 119)

\section{Conceituando estudo de caso}

0 estudo de caso é apenas uma das muitas maneiras de se fazer pesquisa em ciências sociais. (Yin, 2001, p. 19)

Um dos métodos mais utilizados em pesquisas é o estudo de caso, apesar de existirem quanto a ele algumas críticas, essencialmente referentes à impossibilidade de lhe conferir um rigor científico diante da possibilidade de distorção dos resultados por parte do pesquisador. Yin (2001) cita que "o estudo de casos, como outras estratégias de pesquisa, representa uma maneira de se investigar um tópico empírico seguindo-se um conjunto de procedimentos pré-especificados” (p. 35). Ele descreve os principais preconceitos em relação a esse método, tais como a falta de rigor científico; a confusão conceitual entre o ensino do estudo de casos com a pesquisa do estudo de casos; a ausência de possibilidade de realizar generalização científica pela insuficiência de base; além de ser considerado um procedimento demorado, fator que condiz mais com o passado, segundo o autor. Ele conclui que, na realidade, "bons estudos de caso são muito difíceis de serem realizados" (p. 30).

Martins (2006) identifica os predicados que o estudo de caso deve possuir. Para ele, é necessário que o que o pesquisador busca pesquisar, utilizando-se dessa metodologia, seja 
importante. Isso acontece quando é "original e revelador, eficaz, suficiente e relatado de maneira atraente" (p. 5).

Para Yin (2001),

0 estudo de caso é a estratégia escolhida ao se examinarem acontecimentos contemporâneos, mas quando não se pode manipular comportamentos relevantes. 0 estudo de caso conta com muitas das técnicas utilizadas pelas pesquisas históricas, mas acrescenta duas fontes de evidências que usualmente não são incluídas no repertório de um historiador: observação direta e série sistêmica de entrevistas. (p. 27)

0 autor cita que o estudo de caso, comparativamente ao método histórico, possui a vantagem de poder lidar com uma variedade maior de evidências, além de permitir, no caso da observação participante, a manipulação informal das variáveis utilizadas.

Quando um pesquisador opta pelo estudo de caso, ele pode realizar um estudo de caso único ou múltiplo. Yin (2001) cita que, para ser possível criar generalizações científicas, o ideal é o estudo de casos múltiplos. Para o autor,

\section{[...] casos únicos representam um projeto} comum para se realizar estudos de caso, e foram descritos em duas etapas: as que utilizam projetos holísticos e as que utilizam unidades incorporadas de análise. (p. 67)

A realização de estudo de caso único, segundo Yin (2001), é justificável "se o caso se constituir em um evento raro ou exclusivo ou se servir a um propósito revelador" (p. 67)

0 estudo de casos múltiplos encerra vários casos únicos, fator que, atualmente, tem se mostrado mais presente, ainda segundo o autor. Ele exemplifica com a realidade educacional, na qual as inovações ocorrem em áreas independentes, às vezes, concomitantemente. Yin (2001) cita que

A capacidade de se conduzir seis ou dez estudos de caso, efetivamente organizados dentro de um projeto de casos múltiplos, é análoga à capacidade de se conduzir seis ou dez experimentos sobre tópicos relacionados; poucos casos (dois ou três) seriam replicações literais, a passo que outros poucos casos (de quatro a seis) podem ser projetados para buscar padrões diferentes de replicações teóricas. (p. 69)

A realização de uma pesquisa científica requer, antes de qualquer passo, a identificação do problema, o domínio de alguns conceitoschave, para que se chegue ao tipo de método mais adequado para a consecução dos objetivos. Realizar estudo de casos exige, segundo o autor, algumas habilidades prévias, quais sejam, "treinamento e preparação para o estudo de caso específico, desenvolvimento de um protocolo de estudo de caso e condução de um estudo de caso piloto" (Yin, 2001, p. 79). 0 autor cita que esse método, ao contrário do que genericamente se acredita, não é fácil: é árduo e necessita de planejamento e disposição para aplicar as etapas que ele pressupõe. 0 estudo de caso não se resume a organizar uma série de questionários e aplicá-los simplesmente, ainda que distinguindo os elementos-chave da pesquisa, ou seja, o público-alvo e o que se quer investigar. A clareza acerca das limitações e do cuidado em não manipular as variáveis para validar o problema, bem como a responsabilidade em aplicar os questionários, é fundamental para a idoneidade da análise dos resultados alcançados. A pesquisa utilizando estudo de caso na área das Ciências Sociais está na mesma ordem que o experimento científico está para as Ciências Naturais. É necessário o mesmo rigor e os mesmos cuidados ao manipular as variáveis e os instrumentais da pesquisa.

Um dos passos fundamentais para quem deseja realizar um estudo de caso é a "delimitação da unidade-caso", segundo Gil (apud Boaventura, 2007).

Em sua acepção clássica, a unidade-caso refere-se a um indivíduo num contexto de- 
finido. Por exemplo: um paciente de transplante de coração, antes, durante e seis meses após a cirurgia, no contexto de sua família e do hospital. 0 conceito de caso, no entanto, ampliou-se, a ponto de poder ser entendido como uma família ou qualquer outro grupo social, um pequeno grupo, uma organização, um conjunto de relações, um papel social, um processo social, uma comunidade, uma nação ou mesmo uma cultura. (p. 124)

0 estudo de caso é uma estratégia de pesquisa. Segundo Yin (2001), essa estratégia pode ser utilizada em diversos campos de pesquisa, tais como na ciência política e pesquisa de administração pública; na psicologia e sociologia; nas organizações e nos estudos de administração; em temas sobre a cidade; nas pesquisas de planejamento regional como estudos de planos, bairros ou agências públicas.

Essa estratégia pode permitir ao pesquisador o alcance, o entendimento sobre as questões sociais mais complexas. Para isso, é necessário que o objeto de estudo seja bem definido, assim como os dados que devem ser coletados precisam estar claros. Para além disso, o próprio papel do pesquisador no que diz respeito aos passos da pesquisa e aos cuidados para evitar devem ser considerados. Como exemplo, podese tomar a construção e aplicação dos questionários. Após serem definidas as questões com base no que se busca averiguar, descobrir, é necessário uma primeira aplicação, chamada de aplicação de questionário-piloto. Nessa aplicação piloto, será possível ao pesquisador identificar as possíveis falhas do questionário ou mesmo se ele está efetivamente adequado ao que se pretende. Caso sejam encontradas falhas tais como deixar de fora algo importante ou se uma questão está sendo malcompreendida pelo público-alvo, é possível rever, acrescentando, reformulando ou retirando partes antes de dar prosseguimento ao todo da pesquisa.

A confusão conceitual pode comprometer o resultado do trabalho. A formulação equi- vocada do questionário pode custar ao pesquisador a perda de informações ricas, que seriam cruciais para uma melhor abordagem do problema e, assim, uma melhor compreensão de questões mais complexas.

Outro exemplo da necessidade de planejar as etapas do estudo de caso diz respeito às entrevistas. Caso seja necessário realizá-las, o pesquisador necessita planejar o que se quer conhecer, evitando, assim, perda de foco. A entrevista pode ser estruturada ou semiestruturada, além de existir a possibilidade de deixar o entrevistado livre para abordar a sua história de vida, permitindo ao pesquisador analisar determinado fato que aquela história aborde.

As entrevistas estruturadas possuem um foco mais centrado, porém há um risco de inibir determinadas informações que, caso o entrevistado estivesse em uma situação mais espontânea, acabaria abordando. Tudo está intimamente relacionado aos objetivos do pesquisador e ao tipo de pesquisa que ele está desenvolvendo.

Com relação à classificação, o estudo de caso pode ser exploratório, descritivo ou analítico. 0 exploratório objetiva a obtenção de informações preliminares acerca de determinado objeto. Com relação à característica descritiva, o estudo de caso objetiva descrever o que está sendo investigado, estudado, ou seja, o objeto focal. A característica analítica refere-se ao manejo do objeto em questão, visando problematizá-lo, assim como pode servir para construir uma nova teoria ou mesmo questionar outra ainda vigorando. Todos os passos do processo de pesquisa demandam do estudante ou do pesquisador uma postura de seriedade e compromisso com o seu objeto, evitando manipulações que comprometam o resultado da pesquisa.

Vale relembrar a visão de Descartes (2008), sobre o tipo de postura a ser assumido pelo pesquisador,

E como a multiplicidade das leis proporciona frequentemente escusas aos vícios, de sorte que um Estado é muito melhor administrado quando, tendo embora muito pou- 
cas, são elas de preceitos que se compõe a lógica, julguei que me bastariam as quatro seguintes, contanto que tomasse uma firme e constante resolução de nem uma só vez deixar de os observar. 0 primeiro era não receber jamais como verdadeira qualquer coisa, sem antes a conhecer evidentemente como tal, isto é, evitar cuidadosamente a precipitação e a prevenção, e não incluir nos meus julgamentos nada que se não apresentasse tão clara e distintamente ao meu espírito que não tivesse nenhuma ocasião de o pôr em dúvida. 0 segundo, dividir cada uma das dificuldades que tivesse que examinar no maior número possível de parcelas que se tornassem necessárias para melhor as resolver. 0 terceiro, concatenar em boa ordem os meus pensamentos, começando pelos objetivos mais simples e mais fáceis de conhecer, para subir pouco a pouco, como por degraus, até ao conhecimento dos mais complexos, e admitindo mesmo certa ordem entre aqueles que não precedem naturalmente uns aos outros. E o último, fazer a propósito de tudo recenseamentos tão complexos e revisões tão gerais que me sentisse certificado de nada omitir. (p. 25)

Conforme o explicitado, evidencia-se o método do estudo de caso como uma estratégia para se conduzir uma pesquisa empírica, exigindo uma preparação prévia por parte do pesquisador e a organização de um planejamento da pesquisa. 0 método do caso, ferramenta pedagógica inventada em fins do século XIX, se constitui em uma maneira de conduzir a educação de advogados, juristas e administradores de empresa, nada tendo, portanto, de similar com o método de estudo de caso.

Todos os autores trabalhados no presente artigo convergem no que concerne à importância do planejamento e do cuidado em se utilizar desse método, evitando-se trabalhos superficiais ou que nada tragam de novo. Isso não significa que o fato de trabalhar temas já abordados seja inútil do ponto de vista científico, antes, aponta na direção da necessidade em inovar no tipo de abordagem que se dará ao tema por meio da formulação de um problema novo.

\section{Uma abordagem histórica sobre as origens dos dois modos de pensar: o dedutivo e o empírico}

James Bryant Conant (1968), autor do livro Dois modos de pensar, foi um químico, ex-presidente de Harvard, alto funcionário americano na Alemanha e estudioso da educação pública. Segundo ele próprio, foi durante sua temporada como presidente na Universidade de Harvard que percebeu as inquietações que circulavam nas escolas de Direito e Administração de Negócios. Após ler uma palestra do Lord MacMillan sobre os dois modos de pensar, comparando o Direito na Europa e na Inglaterra e nos EUA, ele concluía que os primeiros pensavam dedutivamente e os ingleses e americanos, empiricamente. Posteriormente, já na Alemanha, ele chega ao que parecia ser a resposta para as inquietações percebidas, ou seja, é a ciência social comparável com a ciência natural? Nesse período, as Ciências Sociais não gozavam do mesmo status que as Ciências Naturais, exatamente pela aparente incapacidade de mensurar ou avaliar com rigor científico os seus fenômenos.

Além de buscar diferenciar como os distintos espaços pensavam os problemas humanos - se empiricamente ou dedutivamente -, surgiu a necessidade, a inquietação em compreender a razão das Ciências Sociais terem se desenvolvido de forma especial nos Estados Unidos. Comparando a Educação nos dois continentes, as diferenças foram marcantes. Enquanto que os Estados Unidos possuíam uma tendência ao modo de pensar empírico/indutivo, a Europa era teórico/dedutiva. Conant descreve o pensamento indutivo como aquele que vai do particular para o geral e o dedutivo, como aquele que vai do geral para o particular.

0 autor ressalta que a própria Ciência Natural foi resultado de um criterioso método empírico/dedutivo. Por meio de experimentos 
gerais, chegaram-se às especializações e as teorias foram sendo criadas. Cientistas que possuíam as duas maneiras de pensar colaboraram para o desenvolvimento das Ciências. Nessa mesma linha de pensamento, segue-se um exemplo de método empírico/dedutivo através da história da descoberta, nos Estados Unidos, da primeira gasolina capaz de operar motores de alta compressão. Segundo relato do Dr. Midgely à Conant (1968), era fim da 1 Grande Guerra Mundial e essa experiência deu-se em um laboratório de uma empresa de petróleo. 0 motor de alta compressão foi uma dedução dos cientistas a partir da análise do motor de baixa compressão que era o usual até então. No entanto, este, de baixa compressão, utilizando gasolina comum extraída do processo de fervura do petróleo, não possuía um desempenho a contento. Imaginaram que poderiam construir um motor de alta compressão que aumentaria o número de quilômetros rodados por litro de combustivel. Com a gasolina existente, o motor de alta compressão batia de maneira descontrolada. Segundo Conant (1968), os cientistas sabiam que havia a possibilidade de se obter um hidrocarboneto chamado benzina por meio da destilação de carvão-de-pedra. 0 problema era o custo. Estava posto o desafio aos cientistas, qual seja, encontrar um combustível barato que tivesse o comportamento da benzina, evitando o bater excessivo do motor.

Um dos cientistas, partindo de teorias em uso na época, imaginou que colorir a gasolina comum com corante vermelho poderia resolver a questão. 0 Dr. Midgely concordou e então o cientista recorreu ao almoxarifado. Não havendo uma tinta capaz de colorir a gasolina de vermelho e diante da pressa do cientista, o encarregado orientou o uso da iodina, produto que também era caro, mas que resolveria o problema. Como cairiam no mesmo impasse do uso da benzina, a orientação do cientista responsável pela pesquisa foi de que fossem ao almoxarifado e, começando pela letra a, testassem todos os produtos capazes de dissolveremse na gasolina, tornando-a vermelha. Eviden- cia-se, assim, um caso típico de experiência e erro, pesquisa puramente empírica que resultou na descoberta do "tetraetilo de chumbo e na fabricação da gasolina anti-knock que se fez variada e geral" (Conant, 1968, p. 45).

Ao escrever o livro Dois modos de pensar (Conant, 1968), o autor aborda a trajetória das Ciências e, em especial, descreve como esta se desenvolveu no século XIX nos EUA e na Europa. Segundo o autor, os Estados Unidos, após a Revolução Industrial, depararam-se com a necessidade de prover alguns instrumentais que dessem subsídios à massa populacional que migrava para as cidades. Após a Guerra de Secessão, quando o Norte industrial e o Sul escravista entraram em conflito, o país começou a vivenciar o impacto das invenções por estas solucionarem com agilidade problemas cotidianos. Dessa forma, tanto as universidades quanto o governo e a própria população só davam atenção ao desenvolvimento das artes práticas. Foi rarefeito o caminhar da teoria nesse período, mas ela esteve presente e subsidiou o próprio processo de experimentação de muitos cientistas na época que utilizaram seus fundamentos para desenvolverem os seus experimentos. Essa realidade se modificou radicalmente no século XX, quando ocorreu uma tendência para a busca da teoria de maneira mais sistemática.

Conant (1968) descreve os inventos de utilidade mundial que se deram no século XIX, dentre eles o código Morse, o telefone, a máquina de descaroçar algodão, a lâmpada incandescente, dentre outros. 0 inventor, segundo o autor, era o herói americano, aquele capaz de resolver problemas reais, que compreendia as necessidades da população, dentre elas o nível de possibilidade de acessibilidade aos inventos. É evidente que esses inventos se beneficiaram do desenvolvimento das teorias eletromagnéticas no campo da eletricidade, do uso dos dois métodos - o empírico/indutivo e o teórico/dedutivo. Para corroborar com a afirmativa, basta a descrição das tentativas e dos erros de Thomas Edison ao desenvolver a lâmpada elétrica. Na verdade, essa invenção não era exata- 
mente uma novidade. Segundo Conant (1968), um inglês por nome Swan já havia mostrado que um filamento de carbono em um bulbo em vácuo poderia ser a base para uma lâmpada elétrica, porém, na Europa, não havia a preocupação com o tipo de material a ser utilizado devido ao custo, fator totalmente relevante para a realidade dos Estados Unidos do século XIX. Segundo o autor, para se chegar a um invento acessivel à população, foram utilizados seis mil filamentos vegetais diferentes, além de aproximadamente três mil tipos de elementos que possuíam carbono: desde o petróleo cru ao queijo. Sem uma teoria para guiá-lo, o inventor seguia com as experimentações até chegar às possíveis generalizações, o que deixa transparecer a tendência americana ao método indutivo, partindo do particular para o geral. Seu objetivo era encontrar um material que fosse possivel seu uso em larga escala, assim sendo, o trabalho incansável era justificável porque o custo era de fundamental importância. Buscavam-se inventos de funcionalidade para a população. 0 material que se adequou foi a fibra de bambu. Não obstante, o autor cita que Thomas Edison, ainda em sua adolescência e formação escolar, apesar de sua vida de poucos recursos, conseguira juntar dinheiro e comprar os livros de um grande químico e físico francês chamado Michael Faraday. Seus experimentos sofreram influência teórica do conhecimento a respeito do eletromagnetismo.

Cabe destacar que as críticas e os desprezo mútuos entre cientistas e inventores durante o século XIX era uma constante. Conant (1968) apresenta um curioso fato retratando a invenção do telefone por Alexander Graham Bell. Segundo o autor, durante uma conferência na Universidade de Cambridge, em 1878, Clerk Maxwell, defensor ferrenho do método teórico-dedutivo, citou o seguinte a respeito do telefone:

Quando há cerca de dois anos, chegou-nos a notícia do outro lado do Atlântico, que se havia inventado um método de transmitir, por meio de eletricidade, os sons articulados da voz humana de modo a se poder ouvi-la a centenas de quilômetros distância, todos tínhamos razão de acreditar que a notícia era sem fundamento e começamos a imaginar que prodígios de habilidade construtiva não teriam sido precisos para esse triunfo, que ultrapassaria em delicadeza e complexidade o sifão registrador de William Thompson, assim como este está além de uma simples campainha. Quando, por fim, o pequeno instrumento apareceu, consistindo em peças com que todos estávamos familiarizados e que qualquer amador poderia armar, o desapontamento que nos trouxe a humilde aparência do aparelho só foi parcialmente diminuído ante a verificação de que era mesmo capaz de falar. (p. 70)

Posteriormente, a comunidade científica saudou o invento de Graham Bell, conferindolhe o imensurável valor que ele representou e ainda representa para a humanidade. Conant (1968) cita que esse comentário de desdém de Maxwell não correspondia a todos os cientistas ante o invento de Bell, mas aponta para o abismo entre os dois modos de pensar típico do século XIX. A passagem ainda confirma a tendência a inventos de utilidade pública. Bell era um gênio inventivo. Sua família sempre esteve ligada a melhorias da eloquência, desenvolvendo métodos que facilitassem a vida de surdos e mudos, sendo sua mãe surda. Dessa forma, sua busca incansável por melhorias para a qualidade de vida de pessoas com o mesmo tipo de problemas levou-o, dentre outros inventos, ao telefone. Em 2002, o Congresso dos Estados Unidos delegou a patente de invenção do telefone a Antônio Meucci, Resolução 269 de 11-06-2002.

A finalidade em apresentar essa tendência inventiva, esse ambiente propício dos Estados Unidos do século XIX, se deve ao fato de o autor objetivar justificar uma das mais significativas invenções ocorridas naquele país e que não foi de um objeto, mas de um método pedagógico, utilizado no ensino dos advogados, juristas e administradores de empresa. Foi 
o método do caso (case method) criado por Christopher Columbus Langdell na Universidade de Havard.

\section{Análise do método do caso de Langdell}

Christopher Collumbus Langdell foi um estudioso do direito em Harvard, tendo conhecido Charles William Elliot ainda nos tempos de estudante. Quando esse se tornou Presidente de Harvard, vinte anos mais tarde, chamou Langdell para Deão ${ }^{1}$ da escola de Direito e, logo depois, lhe deu carta branca para desenvolver suas ideias e, assim, aplicar o método do caso naquela instituição. Foi uma revolução na forma do ensino, uma vez que esse método objetivava o estudo prático da lei. Era o estudo da lei viva. A partir da análise dos arrazoados dos juizes, os alunos iam chegando às próprias conclusões sobre a legislação. Não se debruçavam apenas nos compêndios como era o caso do estudo na Alemanha.

Conant (1968) cita que como qualquer método novo, é necessário que o tempo esteja maduro para ele, pois há sempre resistência. E não foi diferente com o método de casos. Era uma maneira de dar aos estudantes a possibilidade de chegarem ao conhecimento teórico, confrontando o próprio entendimento sobre o Direito. A teoria pura não era o foco, mas o fim ao qual se chegaria a partir do entendimento desse mesmo Direito vivenciado por profissionais da área.

Conant (1968) expressa o pensamento de Langdell da seguinte forma:

0 esforço de cada estudante de direito, afirma ele, deve ser o de adquirir o comando dos princípios e doutrinas do direito. Cada uma dessas doutrinas, prossegue Langdell, “chegou a sua presente situação passo por passo, ou, por outras palavras, constituiu um crescimento que, em muitos casos, se estendeu através dos séculos. (p. 76)

Continua o autor a citar o próprio Langdell:
Esse crescimento deve ser reconstituído na sua maior parte através de uma série de casos; e o mais curto e melhor, senão o único modo de domínio efetivo da doutrina está no estudo dos casos em que esteja ela incorporada. [...] Sob esse sistema o estudante deve olhar para o direito como uma ciência constituída por um corpo de princípios a ser encontrado nos casos julgados, os casos sendo para ele, o que o espécime é para o geólogo. (p. 77)

Conant (1968) cita que pelo menos uma escola de Direito foi aberta apenas para contestar esse método. Ainda segundo o autor, foram necessários vinte anos para que o método de casos ganhasse a respeitabilidade e confiança a ponto de ser adotado por outra instituição de ensino. Assim, em 1890, a Columbia University adotou o novo método.

0 autor cita um respeitado professor de Direito, o austríaco Redlich, acerca de sua visão sobre o método do caso:

0 método de casos é uma criação inteiramente original dos americanos nos domínios do Direito [...], é, na realidade, particularmente digno de nota que essa nova criação no ensino do direito comum tenha partido do pensamento de um único homem. Christopher Collumbus Langdell, o qual, como o fundador do método, tornou-se o reformador da escola de direito de Harvard e daí das escolas de direito das universidades americanas em geral. [...] método de casos é, assim, de certo modo, nada mais do que os princípios de educação legal exigidos pela própria natureza do direito comum. [...] a análise crítica do caso legal foi estabelecida como a aplicação do método indutivo, único completamente adaptado à natureza do direito anglo-americano. (p. 79)

Ou seja, o método de casos modificou radicalmente a metodologia de ensino norte-

1. 0 mesmo que diretor. 
americana. Antes dele, os estudantes memorizavam a matéria sistematicamente apresentada nos manuais de Direito. A mudança foi radical: da memorização para a análise dos casos, para o "processo puramente analítico do material do direito comum" (Conant, 1968, p. 78).

Ainda buscando comprovar como o método do caso revolucionou o ensino do Direito e também, posteriormente, da Administração de Empresas, Conant (1968) cita Benjamin N. Cardozo, juiz da Suprema Corte nos Estados Unidos:

0 direito comum não opera por conclusões derivadas dedutivamente de verdades préestabelecidas de validade universal e inflexível. Seu método é indutivo, retirando dos particulares as suas generalizações. [...] Em seu esforço de dar ao senso social de justiça expressão articulada por meio de normas e princípios, o método dos especialistas do direito foi sempre experimental. As regras e princípios do direito comum (case law) nunca foram tratadas como verdades finais, mas como hipóteses de trabalho continuamente testadas e retestadas nos grandes laboratórios do direito, que são as Cortes de Justiça. (p. 84)

Conant (1968), ao demonstrar o modo empírico/indutivo de pensar americano, o põe em contraste com o método teórico/dedutivo dos alemães. Para esse autor, sua tese é de que "são os dois sistemas de ensino que fixam a preferência pelos dois métodos de pensamento" (p. 86).

0 autor cita que o Direito era visto por Langdell como uma ciência, não a ciência como a concebiam os teóricos/dedutivos, mas como a concebiam os inventores do século XIX como Bell ou Edison, uma ciência empírico/indutiva. Para os europeus, o direito como ciência era comparado à matemática, exposto em aulas-conferência. Uma teoria exata em que não cabia questionamentos e análises a partir dos arrazoados, da jurisprudência, mas dos livros de teoria do Direito já consagrados. Os alunos não eram oportunizados a analisarem a jurisprudência, não se aproximavam dos casos reais, apenas da teoria, e essa metodologia não garantia a mesma experiência que os alunos americanos vivenciavam. Eram os alemães especialistas em teoria.

0 autor salienta que, em grande medida, aqueles que buscavam altos cargos se dedicavam ao estudo do Direito. Nem sempre advogavam, mas ocupavam posições de importância nos dois países, talvez sendo essa uma das razões pelas quais existiam as diferenças entre alemães e americanos no que tange à formação. Aqueles que receberam uma formação no estudo de caso do Direito, "adquirem uma atitude de exame, uma desconfiança de amplas generalizações e um preconceito antitotalitário" (Conant, 1968, p. 89). A Alemanha, com essa postura, estava mais apta a formar tecnocratas.

Langdell partiu de um raciocínio lógico, óbvio, porém controversamente inovador. Os advogados e juizes utilizavam-se largamente das decisões e opiniões judiciárias para fazerem seus arrazoados. 0 que justificaria não os utilizar no ensino dessas profissões uma vez que esse material, ainda segundo o autor, poderia ficar à disposição dos estudantes na biblioteca da universidade?

0 método do caso também foi utilizado na formação dos administradores de empresas. Segundo Conant (1968), na Universidade de Harvard, o método de casos foi adotado na Harvard Graduate School of Business Administration por meio do Deão Wallace Donham, que fora um estudante de Direito dessa mesma instituição no começo do século. Segundo passagem de um relatório de comportamento publicado pela Universidade de Harvard,

0 método de caso usado na Escola (Harvard Business) baseia-se no princípio de que se aprende fazendo. Visa desenvolver a capacidade do estudante de tomar decisões acertadas e entrar em ação, criando-lhe condições para isto adequadas. Procura-se pô-lo constantemente em situações em que, como administrador, deve não somente avaliar os 
fatos e pesar as opiniões como também agir com responsabilidade [...]. 0 método de caso em uso na escola já por longo tempo tem dado ênfase aos problemas de tomada de decisão em situações de negócios realísticas e concretas [...]. Depois da guerra, entretanto, a instrução na escola vem dando a maior importância ao fato de que problemas práticos de negócios envolvem não só aspectos próprios relativos à tomada de decisão no contexto da comunidade mas também aspectos administrativos, em que o problema é o de como levar a cabo a tarefa proposta [...]. A instrução, quase completamente feita pelo método de caso, utiliza para isto não somente os estudos econômicos em que se baseou a escola originalmente, mas agora também a adaptação aos problemas de administração de empresa dos conhecimentos, habilidades e métodos de análise derivados de todas as ciências do comportamento. (p. 89-90)

Vale uma rápida analogia com as propostas educacionais que ganharam notoriedade na contemporaneidade baseadas nos princípios construtivistas vigotskyanos.

0 autor salienta a diferença entre os cursos subgraduados e os pós-graduados, onde era aplicado o método do caso por haver uma maturidade por parte dos estudantes, fator que possibilitava a aplicação do método. Assim se dava o processo, segundo texto do relatório da faculdade - Behavioral Sciences at Harvard:

\footnotetext{
A maior parte dos projetos de pesquisa na Harvard Business Scholl envolve investigação de campo e observação para comprovar o que os homens de negócios de fato consideram e fazem ao lidar com um problema particular. Na verdade, esse tipo de pesquisa empírica representa uma abordagem indutiva, através da qual a comparação, análise, interpretação e avaliação da experiência assim colhida dos negócios revelará, se houver, as úteis generalizações. (Conant, 1968, p. 90)
}

0 autor cita que a formação dos futuros homens de negócios, pelo menos em Harvard, está comprometida com o método de pensar empírico/indutivo.

Os europeus, segundo o autor, se opõem a essa postura. Da mesma forma que se dá a formação no curso do Direito por meio de aulas-conferência, os estudantes da Administração ouvem aulas-conferência sobre princípios de Administração do Comércio e sobre tópicos relacionados com estudos econômicos, além de participarem de seminários sobre comércio e problemas econômicos. Não há um programa fixo de estudo. Quando o estudante sente-se preparado, realiza os exames que já são para o diploma. Para o autor, as formações dos juristas, advogados e administradores de empresa nos Estados Unidos e na Alemanha, mediante os exemplos dados, refletem as mesmas predileções opostas do modo de pensar.

Na Alemanha, segundo Conant (1968), o estudante que objetiva entrar para a universidade, desde os dez anos, já se matricula em uma escola preparatória. É um longo e árduo caminho. Após certo período, passam por exames preparatórios. Nessa sequência, muitos desistem ou são levados a desistir. A pós-graduação americana também seleciona de maneira rigorosa seus estudantes, comparando-se, dessa forma, ao padrão europeu. No entanto, o autor cita que no quesito geral de formação há um rigor alemão superior ao americano, além da diferença nos tipos de curso ofertados. Na subgraduação americana, que possui quatro anos de duração, são ofertados cursos como datilografia elementar e avançada, administração de estação de rádio, associações de comércio, corretagem de imóveis, portaria de hotel, manipulação e distribuição de materiais, conclusão de transação de imóveis, administração de aeroportos, correspondência de relações públicas, operações de pequenas lojas e processo de reclamação de frete que, segundo Conant (1968), diferentemente dos alemães, "caracterizam-se pela diversidade, flexibilidade e total falta de uniformidade em relação a padrões de graus e diplomas" (p. 92). 


\section{O método do caso no Brasil}

Atualmente no Brasil, tanto nas graduações de Direito e de Administração de Empresas como em Marketing e áreas de saúde, o estudo do método do caso, chamados case, tem sido utilizado. Partindo da experiência, de realidades vivenciadas, os estudantes confrontam a teoria com a prática. Visto como algo inovador, que de fato não deixa de ser, esse formato, como fora mostrado acima na descrição do método do caso de Langdell, possui uma longa trajetória, tendo nascido, efetivamente, nos fins do século XIX. É necessário ficar claro que o método do caso não se constitui de fatos fictícios. A análise ocorre a partir de casos reais. Os professores se utilizam de experiências das empresas em suas trajetórias e aplicabilidade, dos avanços na área tecnológica, de logística, de pessoal e administrativa para levar os estudantes a refletirem e analisarem situações reais. $\mathrm{Na}$ área do Direito, as jurisprudências são parte importante das aulas dos estudantes, além de serem material para os processos avaliativos, o mesmo acontecendo na área da Medicina, por exemplo, na qual casos de pacientes são tomados como experiências a serem analisadas pelos estudantes. Essa forma de abordagem recebe o nome de análise de cases.

0 que explicaria então a adesão completa a essa metodologia de ensino aqui no Brasil? Segundo Boaventura (2007), esse fato deve-se, essencialmente, à tradição do Direito Romano e do Direito Canônico.

O Brasil enquadra-se na tradição legal do direito, escrito e continental. [...] juntamente com o Brasil, França, outros países europeus e nações ibero-americanas seguem a tradição romanística. (p.123)

Apesar das mudanças paulatinas que se processam, o uso da lei viva como ferramenta pedagógica ainda não é uma prática majoritária dentro das academias brasileiras, metodologia que possibilita aos estudantes um conhecimen- to construtivo, onde ele é levado a concluir sozinho, analisando casos reais, a respeito das teorias. Segundo Boaventura (2007):

A tradição legal do direito escrito, positivo, predominantemente ensinado de forma dedutiva, herdeiro do Direito Romano, do ponto de vista científico e não de ordem legislativa, caracteriza-se pelo primado do processo legislativo, com atribuição de valor secundário às demais fontes do direito para Miguel Reale (1988). É o sistema de lei-código, da lei originária do legislativo como fonte de autoridade primária do direito. Essa tradição romanística enriqueceuse ainda mais com o Direito Canônico e com as práticas comerciais desenvolvidas na ldade Média, de onde resultou o Direito Comercial. Além disso, a Revolução Francesa e a filosofia do direito natural acentuaram a tendência à codificação. A ênfase racionalista coloca a lei como expressão maior e mais autêntica da vontade da $\mathrm{Na}$ ção. É a fonte do direito, por excelência, por tradição romanística. (p. 121)

Martins (2006) distingue o que vem a ser método do caso, ferramenta pedagógica, diferenciando-o de situações que pedem um estudo de caso. Para ele, um

[...] case, ou um estudo de caso é - técnica de ensino em que o professor (instrutor) explica - ensina - determinado conteúdo após os alunos estudarem um caso, geralmente relatando uma situação real já ocorrida. (p. 7)

O Brasil possui uma tradição, de modo geral, dedutiva no modo de pensar e ensinar. Ainda assim, o uso do método do caso pode se configurar como uma nova mentalidade no processo pedagógico dentro das academias e que corrobora consubstancialmente para a formação dos futuros profissionais.

Acerca do tipo de caso a ser trabalhado nas academias, Coelho (2007) cita: 
O caso desenvolvido para uso didático deve envolver situações de realidade, junto com fatos, opiniões e preconceitos existentes sobre o caso, que estejam sendo veiculados por diferentes fontes ou publicados na mídia. Em outras palavras, um caso complexo pode ser construído de modo a apresentar situações reais que possibilitem que os alunos desenvolvam análise, discussões e que tomem decisões finais quanto ao tipo de ações que deveriam ser desenvolvidas se estivessem atuando sobre a situação; mas, por outro lado, podem romper o rigor metodológico do método do estudo de caso, vez que a inclusão de opiniões não faz parte de um método científico (a não ser que as mesmas sejam o próprio objeto de estudo...). No método do caso isto é permitido porque aproxima o aluno da realidade, obrigando-o a separar os dados do problema das informações irrelevantes frequentemente presentes no ambiente profissional. ( $\mathrm{s} / \mathrm{p}$ )

Ainda sobre a formação dos advogados no Brasil, Boaventura (2007) constata que o "Direito manifesta-se na documentação legal, jurisprudencial, nos usos e costumes jurídicos, nos princípios gerais de direito e no poder negocial”. Segundo o autor, “todas essas fontes são tomadas como materiais na investigação jurídica” (p. 98). Entretanto, o autor cita Adeodato (apud Boaventura, 2007) que ressalta que os juristas, quando publicam seus tratados doutrinários, pouco utilizam esses materiais de teor essencialmente prático, ainda que em seu cotidiano profissional se utilizem deles a todo o momento. Isso corrobora para confirmar essa dualidade no próprio processo de ensino, na característica pedagógica que os cursos de Direito no Brasil ainda carregam.

Para Coelho (2007), o método do caso não se esgota em si, ou seja, assim como um mesmo problema pode exigir a combinação de métodos de investigação diferentes para ser possível compreender a realidade, "a arte de ensinar não pode (ou talvez não deva) estar alicerçada sobre uma única alternativa de ensi- no" (s/p). Atentar para o ciclo de aquisição do conhecimento dentro de cada curso ou disciplina é essencial para uma escolha adequada de métodos ou técnicas de ensino condizentes com cada etapa em que se encontra o estudante.

\section{Conclusão}

0 trabalho objetivou diferenciar dois elementos, quais sejam, o método de estudo de casos, utilizado para a realização de pesquisas, segundo Yin, quando levam a questionamentos do tipo "como" e "por que" quando o controle que o investigador tem sobre os eventos é muito reduzido ou quando o foco temporal está em fenômenos contemporâneos dentro do contexto de vida real, não sendo, ao contrário do que se pode imaginar de maneira equivocada, um método largamente utilizado devido à facilidade de aplicação e menor rigor científico; e a ferramenta pedagógica, denominada método do caso, desenvolvida por Christopher Columbus Langdell na Universidade de Havard, na escola de Direito ainda no século XIX e direcionada para o ensino de advogados, juristas e administradores de empresa, cujo foco estava em utilizar-se de princípios, de arrazoados, da jurisprudência, da lei viva para compreender os processos, em vez de os estudantes somente debruçarem-se sobre a teoria pura, sem contanto abrir mão dela. Na verdade, buscava-se possibilitar uma autonomia do pensamento por meio da vivência do Direito real, no qual o professor conduziria os estudantes a partir da análise da prática à conclusão acerca da teoria. Um caminho inverso considerando o modelo tradicional. Surgia daí a necessidade de utilização de súmulas jurídicas. Método esse que diferencia, essencialmente, segundo Conant (1968), dois modos de pensar os problemas humanos, quais sejam, o empírico e o dedutivo: o primeiro, característico do mundo angloamericano; e o segundo, do mundo europeu. Importante também frisar o uso no Brasil dessa metodologia, ainda não sendo, contudo, preponderante nos cursos que a utilizam. Apesar 
de evidenciar um começo sobre essa visão interdisciplinar de pensar o ensino acadêmico e a preparação de futuros profissionais dentro de uma perspectiva mais realista do que venha a ser a problemática cotidiana, o que não exclui o uso da teoria, antes a reforça por solicitar do estudante um posicionamento seguro diante de um caso de maneira justificada, o método do caso, quem sabe pelo fato de a experiência brasileira ser mais dedutiva do que indutiva, ainda caminha de forma tímida nas academias brasileiras.

Apesar de não estar amplamente difundido, já é possível vislumbrar nos cursos de Administração de Empresas, por exemplo, a utilização de muitos casos reais durante as aulas e para os trabalhos de avaliação do conhecimento dos estudantes. Essa postura busca apresentar uma situação real dentro das organizações no que tange ao formato da administração, saindo da verticalidade para a horizontalidade, assim como a análise do uso da tecnologia a serviço da logística, das estratégias de marketing, dentre outras áreas da Administração, permitindo a apreciação e tomada de decisões virtuais em cima de situações reais. Esse modelo pedagógico é muito válido porque enriquece o futuro profissional por permitir-lhe o contato com a realidade da Administração. Considerando que a atualidade vem solicitando um novo perfil de administrador, mais comprometido com as questões soci- ais, humanas, dentro das organizações, sendo, portanto, menos tecnocrata, o método do caso é o modelo ideal a ser desenvolvido, considerando as especificidades de cada curso e de cada realidade acadêmica.

A mesma análise se aplica aos cursos de Direito, Medicina, Psicologia, dentre outros, nos quais as situações reais já são tomadas para análise pelos estudantes, confrontando a teoria e a prática. Talvez a dinâmica do mundo moderno concorra para acelerar as modificações que se fazem necessárias durante o processo de formação dos profissionais brasileiros, visando uma maior qualidade e proximidade com a realidade que enfrentarão no mundo de trabalho. Mudanças essas que estão bem delineadas em níveis outros de formação como, por exemplo, o Ensino Fundamental, que em muitas escolas do país, tanto na rede pública quanto privada, conta com uma pedagogia de caráter construtivista, na qual os educandos são levados à construção da própria autonomia no modo de agir, refletir e, consequentemente, construir seu processo de aprendizagem de maneira significativa. Já não mais utilizam o livro didático como única ferramenta de ensino, sobre o qual os estudantes debruçavam-se sem acesso a outras fontes de informação. 0 livro didático hoje é um coadjuvante e o educando, o objetivo maior de todo o processo ensino/aprendizagem. 


\section{Referências bibliográficas}

BOAVENTURA, E. Metodologia da pesquisa: monografia, dissertação e tese. São Paulo: Atlas, 2007.

COELHO, A. M. R. V. Método do estudo de caso (case studies) ou método do caso (teaching cases)? Uma análise dos dois métodos no ensino e pesquisa em Administração. Disponível em <http://www.pdf4free.com>. Acesso em 21 maio 2007.

CONANT, J. B. A educação de juristas, advogados e administradores de empresa. In: de Anísio Teixeira. São Paulo: Companhia Editora Nacional; Ed. USP, 1968. Dois modos de pensar. Tradução

DESCARTES, R. Discurso do método: meditações. Tradução de Roberto leal Ferreira. São Paulo: Martin Claret, 2008.

MARTINS, G. de A. Estudo de caso: uma estratégia de pesquisa. São Paulo: Atlas, 2006.

YIN, R. K. Estudo de caso: planejamento e métodos. 2. ed. Porto Alegre: Bookman, 2001.

Recebido em 14.08 .08

Aprovado em 09.02.09

Maria Arlinda de Assis Menezes, licenciada em História, especialista em Metodologia do Ensino de História e Cultura AfroBrasileira, mestre em Desenvolvimento Regional e Urbano pela Universidade Salvador (Unifacs), doutoranda em Desenvolvimento Regional e Urbano pela Universidade Salvador (UNIFACS), é professora do Instituto Federal de Educação, Ciência e Tecnologia Baiano. 